\title{
Metal Nanoparticles as Sustainable Tools for C-N Bond Formation via C-H Activation
}

\author{
Federica Valentini, Oriana Piermatti (D) and Luigi Vaccaro *(D)
}

Laboratory of Green S.O.C., Dipartimento di Chimica, Biologia e Biotecnologie, Università degli Studi di Perugia, Via Elce di Sotto 8, 06123 Perugia, Italy; federicavalentinimail@gmail.com (F.V.); oriana.piermatti@unipg.it (O.P.)

* Correspondence: luigi.vaccaro@unipg.it;

\begin{abstract}
The design of highly active metal nanoparticles to be employed as efficient heterogeneous catalysts is a key tool for the construction of complex organic molecules and the minimization of their environmental costs. The formation of novel $\mathrm{C}-\mathrm{N}$ bonds via $\mathrm{C}-\mathrm{H}$ activation is an effective atomeconomical strategy to access high value materials in pharmaceuticals, polymers, and natural product production. In this contribution, the literature of the last ten years on the use of metal nanoparticles in the processes involving direct $\mathrm{C}-\mathrm{N}$ bond formation will be discussed. Where possible, a discussion on the role and influence of the support used for the immobilization and/or the metal chosen is reported. Particular attention was given to the description of the experiments performed to elucidate the active mechanism.
\end{abstract}

Keywords: heterogeneous catalysis; metal nanoparticles; $\mathrm{C}-\mathrm{N}$ bond formation; $\mathrm{C}-\mathrm{H}$ activation

Citation: Valentini, F.; Piermatti, O.; Vaccaro, L. Metal Nanoparticles as Sustainable Tools for $\mathrm{C}-\mathrm{N}$ Bond Formation via C-H Activation. Molecules 2021, 26, 4106. https:// doi.org $/ 10.3390 /$ molecules 26134106

Academic Editors: Matteo Guidotti and Raquel Soengas

Received: 15 June 2021

Accepted: 1 July 2021

Published: 5 July 2021

Publisher's Note: MDPI stays neutral with regard to jurisdictional claims in published maps and institutional affiliations.

Copyright: (c) 2021 by the authors. Licensee MDPI, Basel, Switzerland. This article is an open access article distributed under the terms and conditions of the Creative Commons Attribution (CC BY) license (https:// creativecommons.org/licenses/by/ $4.0 /)$.

\section{Introduction}

Nowadays the development of efficient synthetic strategies to access value-added products in a cost-effective and atom-economical manner is an urgent challenge for modern chemistry. In the context of sustainable chemical production, the use of catalytic methods is therefore of key importance to access reactivity and selectivity that is otherwise inaccessible [1,2].

An effective step-economical catalytic construction of complex organic molecules is based on the use of direct $\mathrm{C}-\mathrm{H}$ functionalization technologies [3-6]. Avoiding the needs of pre-functionalization substrates, the $\mathrm{C}-\mathrm{H}$ functionalization methodology offers an effective approach to minimize the waste associated to the preparation of highly reactive building blocks [3-14]. The formation of $\mathrm{C}-$ metal bonds consecutive to the catalytic $\mathrm{C}-\mathrm{H}$ bond cleavage increases the reactivity of otherwise inert $\mathrm{C}-\mathrm{H}$ bonds, steering direct catalytic functionalization [15-17].

In this scenario, several efforts have been dedicated to the development of various transition metal-based catalysts. Although homogeneous metal complexes are highly efficient in C-H activation reactions [18-26], their difficult reusability and the inevitable waste produced from their separation from reaction products constitutes an important limitation for their actual use. To overcome these issues and improve the sustainability of $\mathrm{C}-\mathrm{H}$ functionalization reactions, the design and use of heterogeneous catalysis is a valid yet challenging option [27-38].

Nanocatalysis have emerged as a well-defined subclass of heterogeneous catalysis that comprehend both colloidal and supported nanoparticles [39-43]. Tailor-made supports and ligands used for the stabilization of metal nanoparticles (MNPs) play a key role in the design of nanocatalysts, influencing both shape and size. The reduced metal dimension at nanoscale makes MNPs potentially highly effective and desirable catalysts. The peculiar properties of nanometric-sized materials make MNPs interesting for their applications in the development of sustainable protocols for $\mathrm{C}-\mathrm{H}$ functionalization reactions. In fact, the 
use of rare precious metals, generally employed in homogeneous catalysis, can be minimized with increased activity at the nanoscale. Indeed, less-reactive non-noble metals also lead to efficient nanocatalytic systems or supports by enhancing their catalytic efficiency. Nanomaterials may also be endowed with specific additional properties that enhance their applicative interest. For example, when MNPs are employed as photocatalysts [44,45], light-activation can promote the single electron transfer mechanism (SET), or alternatively, NPs with magnetic properties can be separated from the reaction mixture, simplifying product isolation [46-53].

Catalyst design strictly influences the operative mechanism of heterogeneous nanocatalysts, and therefore may affect their recoverability and reusability in addition to the metal contamination in the products [35-38]. Indeed, when MNPs are used in catalysis, the catalytic cycle can take place directly on the nanoparticle surfaces (heterogeneous mechanism) or it can be promoted by some soluble species released in solution (homogeneous mechanism). Generally, in the latter case, effective nanocatalysts are of major interest if the metallic active species returns to the surface at the end of the catalytic cycle, defining a "release and catch" mechanism [54,55].

Among the possible transformation of the $\mathrm{C}-\mathrm{H}$ bond, the direct formation of $\mathrm{C}-\mathrm{N}$ bond is of great interest in pharmaceuticals, polymers, and natural products [56-60].

In this contribution, $\mathrm{C}-\mathrm{N}$ bond formation via $\mathrm{C}-\mathrm{H}$ activation processes catalyzed by metal nanoparticles will be discussed, the protocols are divided into $\mathrm{C}-\mathrm{H}$ amidation, $\mathrm{C}-\mathrm{H}$ amination, and $\mathrm{C}-\mathrm{N}$ bond formation in heterocycle synthesis. In the processes described the use of cheap $3 \mathrm{~d}$ metal NPs or their oxides are predominant. Only the synthesis of heterocycles is mostly confined to the employment of Pd-based nanomaterials.

In this literature survey, the selected examples also report data from investigations of the operative mechanisms. These data generally highlight the importance and the role of the support chosen and/or the conditions selected for the synthesis of MNPs to obtain high catalytic efficiencies.

\section{C-H Amidation}

In 2015, Li and coworkers proposed a synthetic strategy for the synthesis of amide 3 using Co NPs embedded in an N-doped carbon matrix (Co@C-N) [61]. The authors tested the influence of pyrolysis temperature on the catalytic activity of Co@C-N in the $\mathrm{C}-\mathrm{H}$ amidation of aromatic aldehydes $\mathbf{1}$ with the amides $\mathbf{2}$ (Scheme 1). With this approach, several catalysts were obtained from pyrolysis of Co containing MOFs and compared with various homogeneous and heterogeneous catalysts. The authors found that the best catalytic system was obtained at $600{ }^{\circ} \mathrm{C}$ and, more importantly, the synergy between Co $\mathrm{NPs}$ and the $\mathrm{N}$-doped carbonaceous matrix seems to be crucial. Among the oxidants tested, the best conditions were found when using 5 eq of tert-butyl hydroperoxide (TBHP) while the increment of oxidants leads to the formation of $p$-toluic acid as side-product. Several analyses have been executed in order to determine the heterogeneous nature of the catalytic process. The catalyst was easily separated from the reaction mixture using and external magnetic field and showed good recyclability for up to five consecutive runs. After a hot filtration test, less than $0.1 \%$ of metal was detected in solution. In addition, TEM analysis after the recovery of the material showed no aggregation of NPs. Furthermore, mechanistic investigation confirmed that the carbonyl in the product came from aldehydes, and the mechanism involved the formation of radicals. Indeed, in the experiment conducted in the presence of TEMPO, no further conversion was observed. After the reaction with ${ }^{13} \mathrm{C}-\mathrm{DMF}$ was carried out, the authors confirmed that the amidation process occurs via $\mathrm{C}-\mathrm{H}$ activation. 


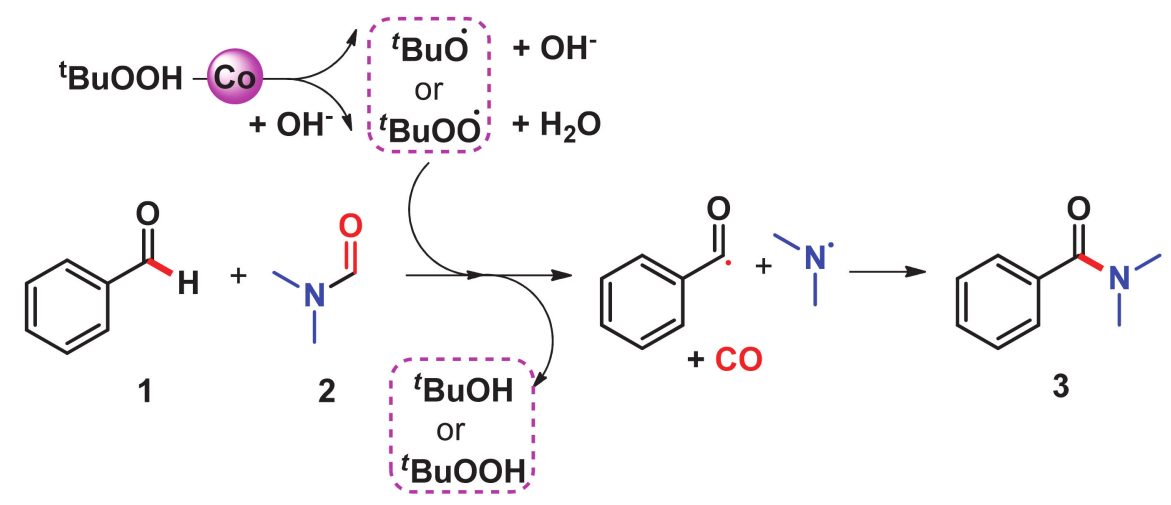

Scheme 1. C-H amidation of aromatic aldehydes catalyzed by Co@C-N $\mathrm{N}_{600}$.

The majority of the protocols developed for the synthesis of $N$-substituted amides are based on the use of copper or copper oxide nanoparticles.

In 2013, Biffis and coworkers examined the influence of different supports on the catalytic activity of $\mathrm{CuO}_{x} \mathrm{NPs}$ in the $\mathrm{C}-\mathrm{H}$ amidation of 1,4-dioxane $4 \mathbf{a}$ or tetrahydrofuran $\mathbf{4 b}$ with chloramine T $\mathbf{5}$ (Scheme 2) [62]. The authors exploited the importance of the surface area and pore volume of the supports in the stabilization of NPs and in their accessibility. In addition, the synthetic strategy for the synthesis of final catalysts allowed different $\mathrm{Cu}$ species on the supports. The authors found that the presence of $\mathrm{Cu}(\mathrm{I})$ was crucial for the activity of the nanocatalyst. Indeed, the best efficiency of the catalyst $\left(\mathrm{CuO}_{x} / \mathrm{SiAl}\right)$ was related to the presence of acidic sites on the support that are responsible for the competitive exchange of the $\mathrm{Cu}$ precursor via a chemisorption hydrolysis process. This exchange leads to the formation of isolated $\mathrm{Cu}(\mathrm{I})$ sites that were difficult to reduce. The selected best nanocatalyst was recycled two times, however the detection of metal leached from the surface suggested homogeneous copper species had a role in making this copper-oxide based catalyst a reservoir of active catalysts.<smiles>OC1COCCO1</smiles><smiles>Cc1ccc(S(=O)(=O)NCl)cc1</smiles><smiles>[Pb]NC1COCCO1</smiles>
or<smiles>[SbH3]NC1CCCO1</smiles>

$6 b$

Scheme 2. $\mathrm{C}-\mathrm{H}$ amidation of 4 catalyzed by $\mathrm{CuO} / \mathrm{SiAl}$ nanocatalyst.

In 2019, Gosh and coworkers reported an atom-economical approach to the synthesis of ynamide 9 via the oxidative alkynylation of amide using molecular oxygen as the sole oxidant [63]. The homogeneously dispersed $\mathrm{Cu}(\mathrm{II}) / \mathrm{Cu}(0)$ nanoparticles stabilized on spherical $\gamma$-MnO supports were efficient in the alkynylation of different oxazolidin-2-one derivatives 8 as well as in the reactions of $N$-methyl- $p$-toluenesulfonamide with aromatic and aliphatic alkynes 7 (Scheme 3). The authors found to be crucial the employment of $\mathrm{Na}_{2} \mathrm{CO}_{3}$ as a base and the presence of oxygen to obtain high yields in a short reaction time $(2 \mathrm{~h})$. The optimized conditions of the gram-scale reaction of phenylacetylene and oxazolidinone led to a $92 \%$ yield. In addition, the authors performed several kinetic experiments to give some insight about the mechanism of the reaction. By conducting the reaction in the presence of radical scavenger like BHT (butylated hydroxyl toluene) and TEMPO, yields comparable with those of the optimized reaction were obtained, suggesting that a radical pathway does not take place. The heterogeneous nature of the reaction was confirmed by a hot filtration test and the catalyst stability was confirmed by a low metal leaching ( $2 \mathrm{ppm}$ ), which allowed for the efficient recovery and reuse the $\mathrm{Cu}-\mathrm{MnO}$ heterogeneous system for five consecutive reactions, maintaining similar productivity. 


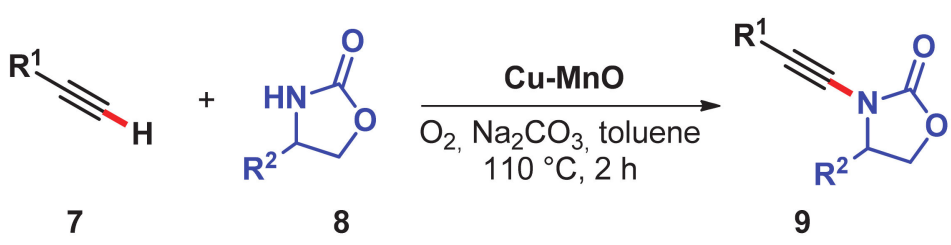

Scheme 3. Oxidative alkynylation of 8 catalyzed by $\mathrm{Cu}-\mathrm{MnO}$.

Recently, the same group proposed a different protocol for the $\mathrm{C}-\mathrm{H}$ amidation of 8-aminoquinoline benzamides $\mathbf{1 0}$ with different cyclic amides $\mathbf{1 1}$ using their $\mathrm{Cu}-\mathrm{MnO}$ heterogeneous catalyst and air as oxidant (Scheme 4) [64]. The authors hypothesized that their MnO support may help the electron transfer pathway in the reductive elimination by working as an electron-transfer mediator (ETM). Indeed, the use of manganese oxide can easily reduce the oxidation gap potential between the reduced catalyst and molecular oxygen, allowing the use of oxygen or air as benign final oxidants [65-68]. The authors also found the use of DMSO as reaction medium and the use of DMAP as base and air as oxidants to be crucial for the entire efficiency of the process. The optimized protocol can be further scaled up to gram scale with comparable yield. Only a slight decrease in catalytic efficiency was observed during recovery and reuse, and the authors mainly attributed this to the sintering of the impregnated copper. Indeed, the authors excluded the possibility of reduced activity related to $\mathrm{Cu}$ leaching by measuring the metal content in solution $(<1 \mathrm{ppm})$. In addition, the heterogeneity of the process was confirmed by a hot filtration test. Additional experiments to better understand the reaction mechanism were also performed. The results obtained by carrying out the reaction in presence of BHT and TEMPO as radical scavengers avoided the presence of a radical pathway. The $\mathrm{k}_{\mathrm{H}} / \mathrm{k}_{\mathrm{D}}$ ratio of 1.04 suggests that $\mathrm{C}-\mathrm{H}$ bond activation was not the rate-determining step. Moreover, after performing the reaction with different designed substrates, the authors concluded that the presence of the $\mathrm{N}, \mathrm{N}$-bidentate ligand was crucial, suggesting that the reaction proceed through dehydrogenative amidation via $\mathrm{C}-\mathrm{H}$ activation. The ortho-selectivity of $\mathrm{C}-\mathrm{H}$ amidation is related to the presence of 8 -amino quinoline as directing group.

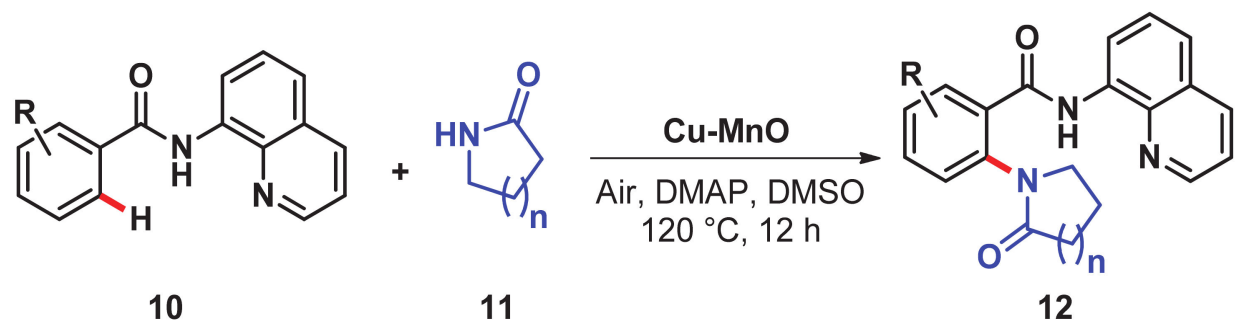

Scheme 4. C-H amidation of $\mathbf{1 0}$ catalyzed by $\mathrm{Cu}-\mathrm{MnO}$.

\section{C-H Amination}

Among the C-H amination processes, Ying and coworkers developed in 2011 a Pd(II)based nanocatalyst for the oxidative amination of acrylates $\mathbf{1 4}$ (Scheme 5) [69]. The catalyst is a Pd-polyoxometalate (POM) supported on a carbon named $\mathrm{Pd}-\mathrm{H}_{6} \mathrm{PV}_{3} \mathrm{Mo}_{9} \mathrm{O}_{40} / \mathrm{C}$, which showed superior catalytic activity in comparison to $\mathrm{Pd}-\mathrm{POM} / \mathrm{C}$ and also $\mathrm{Pd} / \mathrm{C}$. The authors found DMF to be the best medium, and that the presence of $\mathrm{O}_{2}$ was crucial for the oxidative process between diphenylamine and butyl acrylate. The nanocatalyst was recovered and reused for three consecutive runs with the addition of fresh $\mathrm{H}_{6} \mathrm{PV}_{3} \mathrm{Mog}_{9} \mathrm{O}_{40}$ after each cycle. Indeed, the authors measured $70 \%$ of POM lost after the recovery of the catalyst even if no change in the morphology of the Pd NPs was detected from TEM analysis. XPS spectra confirmed the presence of $\mathrm{Pd}(\mathrm{II})$ on the catalyst although after hot filtration test an increase in conversion was detected (from $30 \%$ to $45 \%$ ) suggesting the presence of leached $\mathrm{Pd}$, which acted as catalyst. 


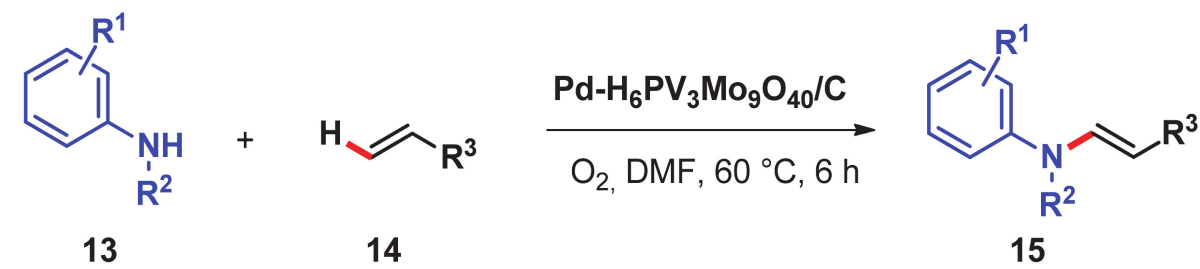

Scheme 5. Oxidative $\mathrm{C}-\mathrm{H}$ amination of acrylates 14 catalyzed by $\mathrm{Pd}-\mathrm{POM} / \mathrm{C}$.

In 2017 Gracia, Dhakshinamoorthy and coworkers reported the direct oxidative coupling of aromatic N-H compounds with different amides (Scheme 6) [70]. The authors investigated the influence of different ratios of Fe and Co nanoparticles embedded in a turbostratic graphitic carbon matrix and found a linear dependence of the enhanced catalytic efficiency with the decrease of cobalt percentage. With the selected Fe@C catalyst, the authors found as optimal reaction conditions the use of TBHP in the presence of an excess of dimethylacetamide (DMA) that acts both as compound for amination and as a reaction medium at $110{ }^{\circ} \mathrm{C}$. After filtering the heterogeneous catalyst, less than $1 \%$ of the initial amount of Fe was detected in solution. To give more insight about the mechanism, experiments with homogeneous Fe species in different oxidation states were performed. In these conditions, product $\mathbf{1 8}$ was detected in $<5 \%$, confirming that the reaction did not proceed with the metal released in solution. However, after filtering the catalyst, the reaction did not completely stop. The reaction was then conducted in presence of TEMPO, leading only to the DMA-TEMPO adduct. By reacting this adduct without the presence of a Fe NP catalyst, a C-N coupling product was observed, suggesting that the role of Fe catalyst was as an initiator of TBHP decomposition. The catalyst was efficiently recovered and reused for five consecutive runs without changes in the reaction rate during the recycle. Indeed, the TEM images of the recovered catalyst are comparable with the images obtained with fresh Fe@C material. Both the Fe NP dimensions and C matrix morphology remained unaltered after the reaction.
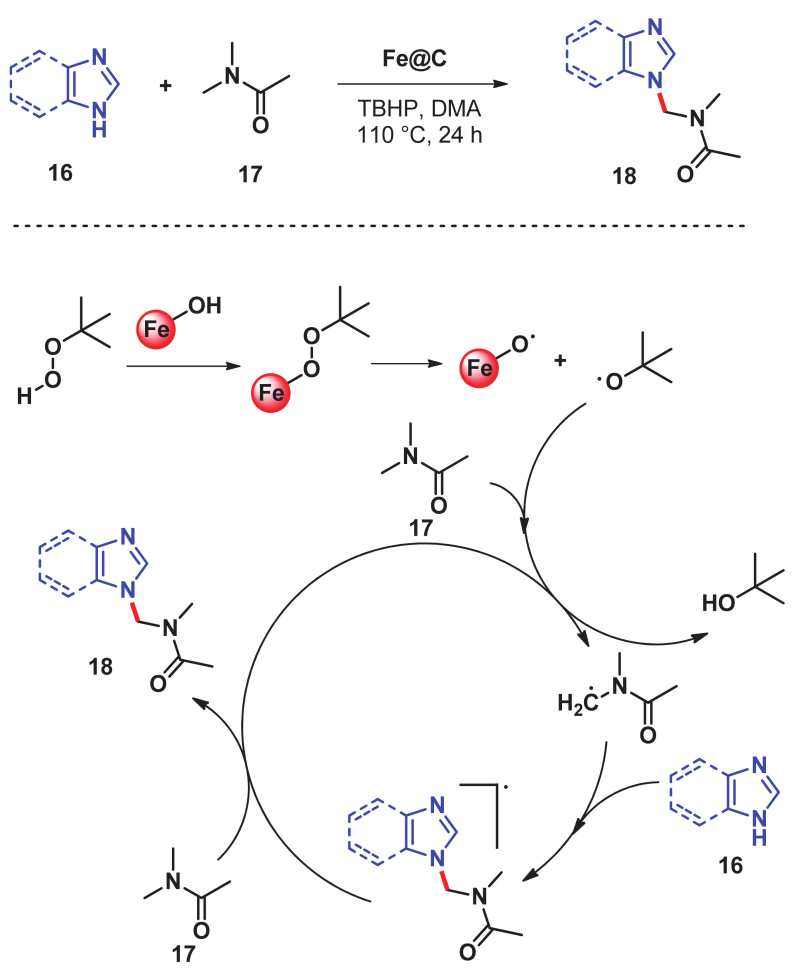

Scheme 6. Oxidative coupling of $\mathbf{1 6}$ catalyzed by Fe@C. 
Different $\mathrm{C}-\mathrm{H}$ amination processes have been developed with the use of copper based nanocatalysts, employing as nitrogen sources primary [71,72] or secondary [64,72-74] amines, as well as ammonia [75].

In 2014 Nageswar and coworkers reported the synthesis of 2-substituted benzothiazoles 21 through direct $\mathrm{C}-\mathrm{H}$ amination catalyzed by magnetic copper ferrite nanoparticles (Scheme 7) [73]. The air-stable $\mathrm{CuFe}_{2} \mathrm{O}_{4}$ nanocatalyst can be easily separated from the reaction mixture thanks to its magnetic properties. This feature allowed the authors to efficiently recover and reuse the catalytic system for four consecutive runs without any loss in conversion. Furthermore, XRD, TEM, and SEM analyses confirmed the stability of the copper ferrite nanocatalyst. However, the authors did not envisage any mechanistic proposal regarding the direct $\mathrm{C}-\mathrm{H}$ amination.<smiles></smiles>

19

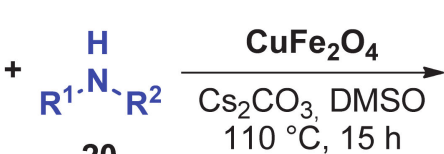

20<smiles>[R1]N([R1])c1nc2ccccc2s1</smiles>

21

Scheme 7. C-H amination of 19 catalyzed by $\mathrm{CuFe}_{2} \mathrm{O}_{4}$.

During the same year, Kantam and coworkers proposed the synthesis of $N$-aryl- $\gamma$ amino- $\gamma$-lactams 24 from 2-pyrrolidinone 22 and aromatic or heteroaromatic amines $\mathbf{8}$, catalyzed by $\mathrm{CuO}$ NPs (Scheme 8) [71]. The authors tested different copper-based catalysts, both homogenous and heterogeneous, and found $\mathrm{CuO}$ NPs to be the best catalytic system in the presence of TBHP as an oxidant. Due to the possibility of generating radicals using $\mathrm{CuO}$ NPs in combination with TBHP, the authors carried out the reaction in the presence of TEMPO and no conversion was detected under these conditions. This result led the authors to propose a single electron transfer mechanism (SET) to afford iminium intermediates after the generation of a radical by tert-butoxyl radicalic abstraction of the $\gamma$-proton of 22 . The catalyst was reused without loss in efficiency. XRD analyses revealed that no change in morphology occurred after the use of the CuO NPs.

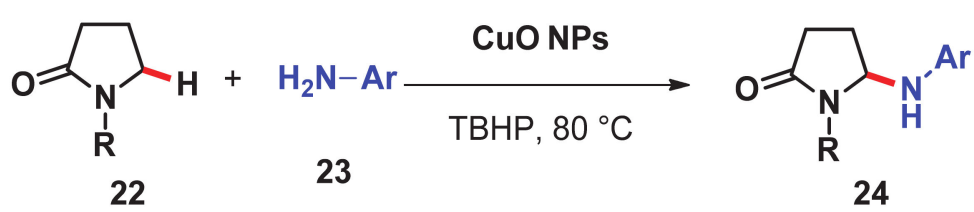

Scheme 8. C-H amination of 22 catalyzed by CuO NPs.

A different protocol for the oxidative amination of benzene 25 to aniline 27 promoted by a $\mathrm{Cu}(\mathrm{II})$-based nanocatalyst in the presence of $\mathrm{H}_{2} \mathrm{O}_{2}$ was developed by $\mathrm{Bal}$ and coworkers (Scheme 9) [75]. The authors used a bimetallic copper-chromium oxide as a support for $\mathrm{Cu}$ (II) NPs $\left(\mathrm{Cu}\right.$ (II)-CuCr $\left.\mathrm{C}_{2} \mathrm{O}_{4}\right)$ and tested different reaction conditions to obtain the best selectivity in $\mathbf{2 7}$ with the lowest amount of phenol formed as side-product. The catalytic activity remainedc unchanged for up to five consecutive runs and no metal leaching was detected in solution, suggesting the heterogeneous nature of the catalyst. In addition, the change in conversion during the experiment in the presence of TEMPO as a radical scavenger led the authors to propose a reaction mechanism which involves the formation of $\mathrm{NH}_{2} \mathrm{OH}$ and a subsequent reduction to protonated amino radicals. Different catalytic tests were conducted by varying the ratio between $\mathrm{NH}_{3} 26$ and $\mathrm{H}_{2} \mathrm{O}_{2}$, proving that the reaction path starts with the $\mathrm{C}-\mathrm{H}$ bond activation of benzene in presence of $\mathrm{H}_{2} \mathrm{O}_{2}$. 


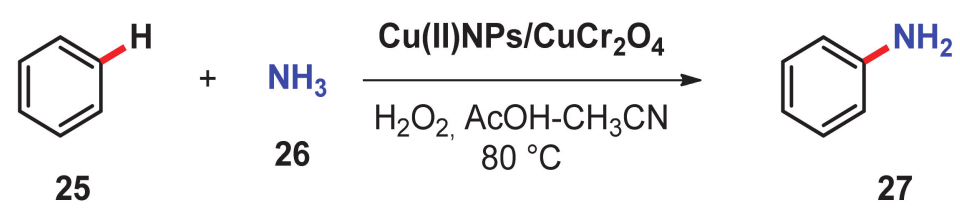

Scheme 9. Oxidative C-H amination of 25 catalyzed by $\mathrm{Cu}(\mathrm{II})-\mathrm{CuCr}_{2} \mathrm{O}_{4}$.

Bhalla and coworkers proposed a supramolecular ensemble of a perylene bisimide (PBI) derivative and $\mathrm{Cu}$ NPs, generated in situ as a photocatalyst for direct ortho $\mathrm{C}\left(\mathrm{sp}^{2}\right)-\mathrm{H}$ amination of benzamide derivative 28 [72]. The authors optimized the reaction conditions by employing $p$-nitro aniline and found that DMSO as medium and the presence of air gave the best conditions for the reaction (Scheme 10). The ortho $\mathrm{C}-\mathrm{H}$ activation could be promoted by a single-electron transfer mechanism (SET) assisted by the electrons on the copper nanoparticle surfaces, which led to the free radical intermediates. A similar mechanism was proposed by the authors for the ortho-alkynylation of $\mathbf{2 8}$ catalyzed by the PBI:Cu NP photocatalyst [72]. The catalyst showed great performance with various anilines $\mathbf{2 3}$ as well as heterocyclic amines, morpholine, pyrrolidine, and piperidine. The PBI:Cu NPs were recycled for up to three consecutive runs. Moreover, in a second step the authors performed directing group cleavage, obtaining the corresponding carboxylic acid 30 in high yield.<smiles>O=C(Nc1ccccc1C1=NCCO1)c1ccccc1</smiles><smiles>CO[R6](=O)[O-]</smiles><smiles>O=C(CN(O)C(=O)O)Nc1ccccc1C(=O)O</smiles><smiles>CCCCCCCC(N)Br</smiles><smiles>O=C(Nc1ccccc1C(=O)Nc1ccccc1C1=NCCO1)c1ccccc1</smiles>

Scheme 10. C-H amination of 28 catalyzed by PBI:Cu NPs and subsequent directing group cleavage.

In 2017 Gosh, Panda, and coworkers reported the oxidative C-H amination of different azoles 31 catalyzed by copper and supported on a lotus-shaped manganese oxide heterogeneous catalyst (Scheme 11) [74]. The designed catalyst was able to overcome the limitations of their previously reported $\gamma-\mathrm{MnO}_{2}$ catalytic system that showed good performance only with benzoxazole derivates [76]. The authors prepared and tested several catalytic systems by varying the loading of $\mathrm{Cu}$ from 2.5 to $10 \mathrm{wt} \%$ in order to enhance the catalytic efficiency by the incorporation of copper into manganese oxide [74]. Only in the $10 \mathrm{wt} \%$ was $\mathrm{Cu}-\mathrm{MnO}$ observed, with peaks associated to both metallic $\mathrm{Cu}$ and $\mathrm{CuO}$ in the XRD analysis, while no $\mathrm{CuO}$ was detected from 2.5 to $5 \mathrm{wt} \%$ of $\mathrm{Cu}-\mathrm{MnO}$ catalysts. The optimal results in the oxidative amination of benzothiazole with morpholine were recorded using $5 \mathrm{wt} \% \mathrm{Cu}-\mathrm{MnO}$ in the presence of oxygen as an oxidant. The catalyst was also efficient in the $\mathrm{C}-\mathrm{H}$ amination of $\mathrm{N}$-methyl benzimidazoles and superior in comparison with $\gamma-\mathrm{MnO}_{2}$ when benzoxazoles were used as substrates. Although the copper in solution after the reaction was lower than 1 ppm, a decrease in catalytic efficiency was detected together with a decrease of surface area during the recovery and reuse for five consecutive runs. The authors ascribed this loss in efficiency to the sintering of $\mathrm{Cu}$ NPs. 


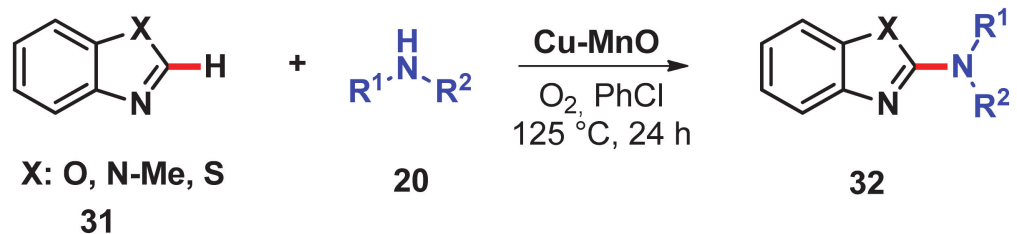

Scheme 11. C-H amination of 31 catalyzed by $\mathrm{Cu}$ supported on lotus shaped $\mathrm{MnO}$.

Very recently, the same group employed copper-supported on spherical $\mathrm{MnO}$ in the $\mathrm{C}-\mathrm{H}$ amination of 8-aminoquinoline benzamides 10 (Scheme 12) [64]. In comparison with the results previously described for the amidation reaction, the direct amination proceeds under milder reaction conditions. After $6 \mathrm{~h}$ at $100{ }^{\circ} \mathrm{C}$, different products were obtained in excellent yields without the addition of any additives. Only the primary amine and indole were not compatible with the optimized reaction conditions. However, when the reaction was scaled up to gram scale, a comparable yield was recorded in the $\mathrm{C}-\mathrm{H}$ amination of 10 with 4-methylpiperidine. For the amidation, the $\mathrm{Cu}-\mathrm{MnO}$ was efficiently recycled for five consecutive runs with negligible loss in efficiency associated with the sintering of the impregnated copper.<smiles>[R]c1ccccc1C(=O)Nc1cccc2c1N=CCC2</smiles>

10<smiles>[R]N[R]</smiles>

20<smiles>[R]c1cccc(N([R])[R])c1C(=O)Nc1cccc2cccnc12</smiles>

33

Scheme 12. C-H amination of 10 catalyzed by $\mathrm{Cu}-\mathrm{MnO}$.

Yan and coworkers developed a bimetallic RuNi nanocatalyst supported on $\mathrm{MgO}$ for the one-pot conversion of glycerol 34 to alanine 36 through the amination of the lactic acid intermediate 35 via C-H activation (Scheme 13) [77]. The authors prepared and tested different bimetallic Ru-based nanocatalysts by changing the metal, the ratio between two metals, the support, and the temperature of calcination. An increase in catalytic activity was observed for RuNi NPs in the molar ratio 1:7, with a range of $500-600{ }^{\circ} \mathrm{C}$ as the ideal temperature for calcination using $\mathrm{MgO}$ as a support. The authors attributed the effect of the support to its chemical stability under the basic reaction conditions, while the temperature of calcination influences the nature of the Ru species as well as the presence of $\mathrm{Ni}$. Indeed $\mathrm{Ru}_{1} \mathrm{Ni}_{7} / \mathrm{MgO}$ presents much more similarity with metallic $\mathrm{Ru}$ than does $\mathrm{Ru} / \mathrm{MgO}$, as deduced from XPS analysis. After kinetic studies, the author suggested that the amination of 35 to 36 via $\mathrm{C}-\mathrm{H}$ activation was the rate determining step. In order to explain the role of $\mathrm{Ni}$ in the catalytic cycle, the authors conducted DFT calculations that suggested that $\mathrm{Ni}$ can enhance the catalytic activity of $\mathrm{Ru}$ in the conversion of lactic acid to alanine by binding the oxygen alkoxide atoms. The catalyst was tested on 56\% purity crude 34 and was recovered and reused three times. During the third run, some decrease in activity was observed, and the authors suggested that this could be related to some increase of NP size after recovery. The oxidation state of the two metals remained unchanged. 


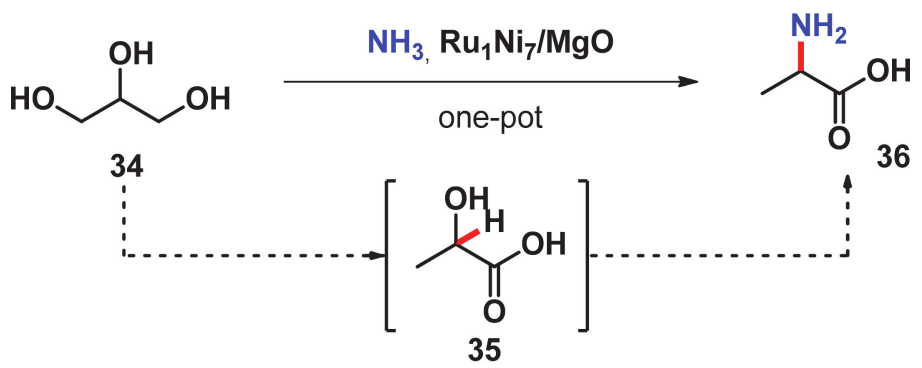

Scheme 13. Alanine production via C-H amination from glycerol waste.

\section{C-N Bond Formation in the Synthesis of Heterocycles}

Particularly intriguing is the preparation of widely useful heterocycles exploiting direct $\mathrm{C}-\mathrm{N}$ bond formation. An example is given by the intramolecular oxidative $\mathrm{C}-\mathrm{H}$ amidation process proposed by Patel and coworkers for the synthesis of 2,3-disubstituted quinazolinones 39 (Scheme 14) [78]. Using $\mathrm{CuO}$ nanoparticles, several quinazolinones were obtained from different orto-halobenzamides 37 and benzylamines 38 in DMF under air via an Ullman coupling followed by an oxidative intramolecular $\mathrm{C}-\mathrm{H}$ amidation. To further confirm the proposed mechanism, the authors performed the reaction under inert atmosphere, obtaining only Ullman's product. The latter was placed under optimized reaction conditions, in the presence of air, affording the desired product and confirming the presence of this intermediate during the reaction. After the recovery and reuse of the $\mathrm{CuO}$ nanocatalyst, a slight decrease in catalytic efficiency was observed due to a change in the morphology of the $\mathrm{CuO}$ material after the recovery. Indeed, TEM images of the used catalyst showed the presence of particle aggregates formed during the reaction.<smiles>[R]c1ccc(NC(=O)c2cc[R1]cc2Br)cc1</smiles>

37<smiles>NCc1c[R]ccc1</smiles>

38<smiles>[R]c1ccc(-n2c(-c3ccccc3)nc3c(c2=O)C=C[R1]C=C3)cc1</smiles>

39

Scheme 14. Oxidative $\mathrm{C}-\mathrm{H}$ amidation for the synthesis of 2,3-disubstituted quinazolinones 39 catalyzed by $\mathrm{CuO}$ NPs.

The majority of processes involved in the direct synthesis of heterocycles are generally catalyzed by Pd-based nanocatalysts.

In 2014 Ying and coworkers developed eight different palladium NP-based catalysts for the synthesis of carbazoles $\mathbf{4 1}$ via intramolecular $\mathrm{C}-\mathrm{H}$ amination (Scheme 15) [79]. The authors investigated the role of the support in Pd stabilization, highlighting the dependence of catalyst reactivity on the interactions between $\mathrm{Pd}$ and the support. After testing $\mathrm{Ag}$ $\mathrm{Pd} / \mathrm{C}, \mathrm{Ag} @ \mathrm{Pd} / \mathrm{C}, \mathrm{Ag}_{2} \mathrm{~S} @ \mathrm{Pd} / \mathrm{C}, \mathrm{Pd} / \mathrm{C}, \mathrm{Pd} / \mathrm{CeO}_{2}, \mathrm{Pd} / \mathrm{TiO}_{2}, \mathrm{Pd} / \mathrm{Al}_{2} \mathrm{O}_{3}$ and $\mathrm{Pd} / \mathrm{SiO}_{2}$ in DMSO as a reaction medium, the highest catalytic activity was that of $\mathrm{Pd} / \mathrm{C}$. This material was then selected for further optimization. The authors found the use of $4 \AA$ molecular sieves crucial to remove the only byproduct, water, formed during the reaction using $\mathrm{O}_{2}$ as oxidant. Despite the good tolerability of the Pd/C catalyst for different substrates, during the recycle experiments the conversion dropped by $12 \%$ and $50 \%$, respectively for the two subsequent recycles. The drop in catalytic efficiency was explained by TEM analyses that revealed an increase of the particle size distribution from $2-5 \mathrm{~nm}$ to $20-30 \mathrm{~nm}$. However, the Pd $3 \mathrm{~d}$ peaks from XPS analyses before and after the $\mathrm{C}-\mathrm{H}$ amination process showed no significant modification of the surfaces. By performing a series of hot filtration experiments, with and without oxygen, the authors proposed a homogeneous nature of the catalysis driven by both $\mathrm{O}_{2}$ and DMSO. Indeed, after the filtration of solid catalyst the 
reaction proceed only in presence of oxygen. The role of oxygen reveals to be crucial for the solubilization of $\mathrm{Pd}(\mathrm{II})$ active species, probably as Pd-DMSO complexes. The same behavior was also revealed when the $\mathrm{CeO}_{2}, \mathrm{TiO}_{2}$, and $\mathrm{Al}_{2} \mathrm{O}_{3}$ Pd-supported nanomaterials were employed. The $\mathrm{Pd} / \mathrm{C}, \mathrm{Pd} / \mathrm{CeO}_{2}$, and $\mathrm{Ag}_{2} \mathrm{~S} @ \mathrm{Pd} / \mathrm{C}$ nanocatalysts presented a higher amount of Pd(II) species than the other materials. Among these, the inactive $\mathrm{Ag}_{2} \mathrm{~S} @ \mathrm{Pd} / \mathrm{C}$ had its $\mathrm{Pd}(\mathrm{II})$-associated peaks shifted to lower values. The authors suggested that the different interactions between $\mathrm{Pd}(\mathrm{II})$ and the supports influenced catalytic efficiency, as it is related to the the dissolution of palladium in DMSO.

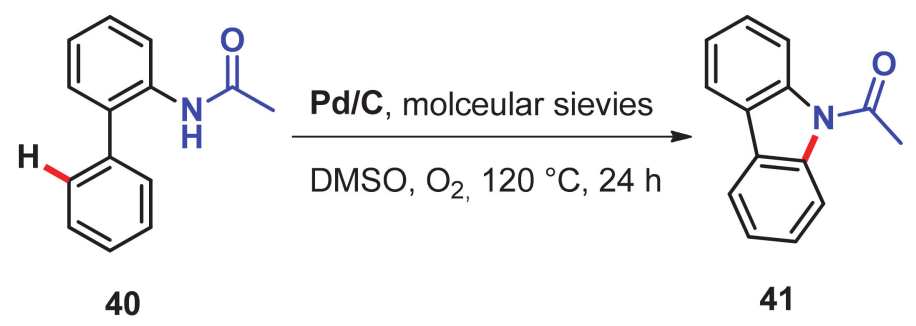

Scheme 15. Intramolecular $\mathrm{C}-\mathrm{N}$ bond formation for the synthesis of carbazoles catalyzed by Pd/C.

During the same year, Arisawa and coworkers reported the synthesis of $N$-arylbenzotriazoles 43 via a sequence of 1,7-palladium migration, cyclization, and dealkylation catalyzed by sulfur-modified gold-supported Pd NPs (SAuPd) (Scheme 16) [80]. The authors focused initially on the choice of the most adequate oxidant to promote the formation of $\mathrm{Pd}(\mathrm{II})$ species and found that $\mathrm{PhI}(\mathrm{OAc})_{2}$ combined with $\mathrm{KOAc}$ as a base and DMF as the medium to produce optimal reaction conditions. The protocol is applicable to different substrates; however, recycling or further tests to determine the mechanism and the nature of the catalysis were reported when compound $\mathbf{4 3}$ was tested as inhibitory of indoleamine 2,3-dioxygenase in vitro.
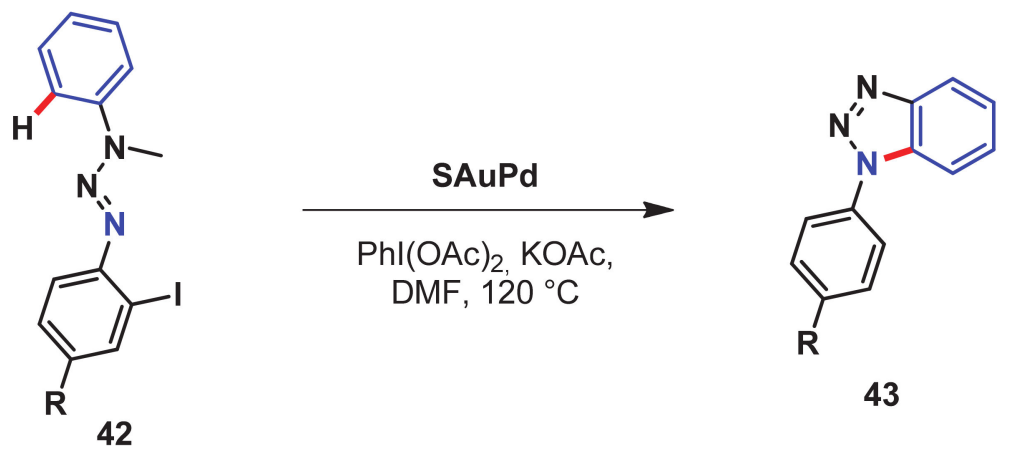

Scheme 16. Synthesis of 43 via sequence of 1,7-palladium migration, cyclization, and dealkylation catalyzed by SAuPd.

In $2014 \mathrm{Wu}$ and coworkers developed an efficient protocol for the synthesis of the $N$-pyridyl indole 46 by coupling $N$-phenyl-2-aminopyridine 44 with disubstituted alkynes 45 (Scheme 17) [81]. An exhaustive screening of the catalyst was performed, varying both the metal and the support. Among the metals tested ( $\mathrm{Pd}, \mathrm{Ru}$, and $\mathrm{Pt}$ ), palladium gave the best results, while replacing the $\mathrm{CeO}_{2}$ support with $\mathrm{TiO}_{2}$ or $\mathrm{Al}_{2} \mathrm{O}_{3}$ gave poor results. With the selected $\mathrm{Pd} / \mathrm{CeO}_{2}$ nanocatalyst, further mechanistic experiments were conducted, suggesting the heterogeneous nature of the catalysis. Indeed, both in the Hg-poisoning test and in the reaction conducted with homogeneous $\mathrm{Pd}(\mathrm{OAc})_{2}$ only poor conversion into product 46 was detected in the reaction mixture. However, during the recycling experiment, an important drop in conversion was observed in the second run. The competitive kinetic isotope experiment revealed that the $\mathrm{C}-\mathrm{H}$ activation was not the rate-determining step. 


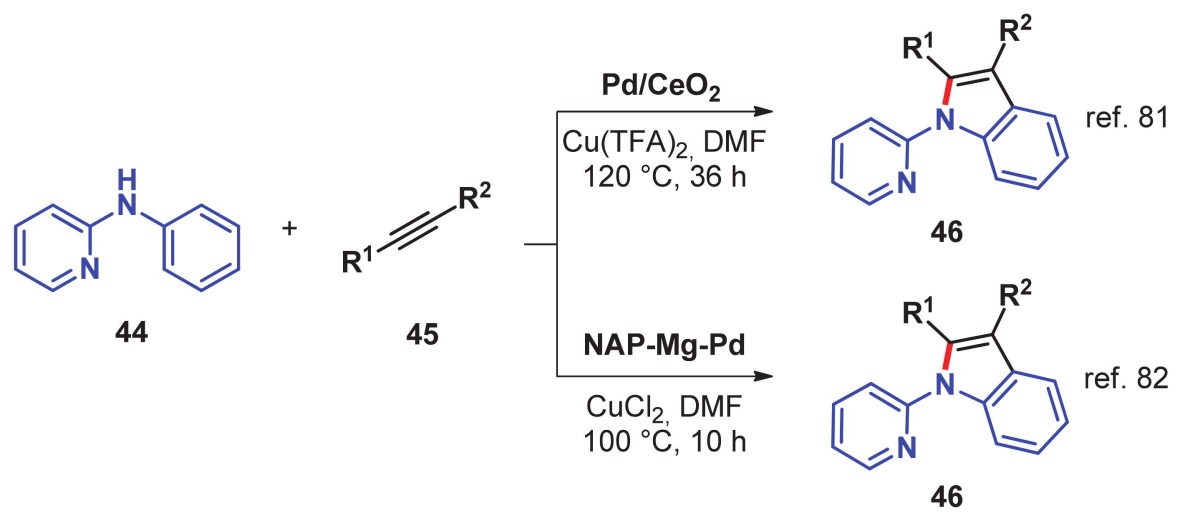

Scheme 17. Synthesis of 46 catalyzed by NAP-Mg-Pd.

One year later, Kantam and coworkers developed an efficient Pd-based heterogeneous catalyst for the same process (Scheme 17) [82]. The authors tested different heterogeneous $\operatorname{Pd}(0)$ NP-based catalysts and found the role of the nanocrystalline magnesium oxide support beneficial to the reaction using $\mathrm{CuCl}_{2}$ as oxidant. The developed catalyst (NAP$\mathrm{Mg}-\mathrm{Pd}(0)$ ) was efficiently recovered and reused for four consecutive runs without loss in efficiency or Pd leaching in solution. Moreover, the comparison of TEM images between the fresh and spent catalysts showed no change in morphology after four cycles. However, further experiments about the reaction mechanism were not reported by the authors.

Recently, Sekar and coworkers developed the synthesis of phenanthridinones 50 via $\mathrm{C}-\mathrm{H}$ activation of $\mathrm{N}$-methoxy benzamides 47 and aryl iodides 48 (Scheme 18) [83]. The authors tested several Pd NPs using different stabilizers and commercially available Pd/C and Pd NP. The best reactivity was observed using binaphthyl for Pd NP stabilization (Pd-BNP) in combination with $\mathrm{Ag}_{2} \mathrm{O}$ as the oxidant and acetic acid as a solvent. In order to further investigate the mechanism, the authors performed different control experiments. In conclusion, they suggested that the mechanism starts with a $\mathrm{C}-\mathrm{H}$ bond activation and selective $\mathrm{C}-\mathrm{C}$ bond formation while the $\mathrm{C}-\mathrm{N}$ bond formation occurs only at the end. In addition, the presence of the $N$-methoxy group was essential for the completion of the process, and specifically for the final $\mathrm{C}-\mathrm{N}$ bond formation. Eventually, the methoxy group can be easily removed ( $45 \mathrm{~min}$ reaction time) in the presence of visible light. UVvis spectra demonstrated that no change in the morphology of the Pd NP occurred after the reaction. Moreover, hot centrifugation and $\mathrm{Hg}$ poisoning tests showed that no metal leaching was detected in solution.

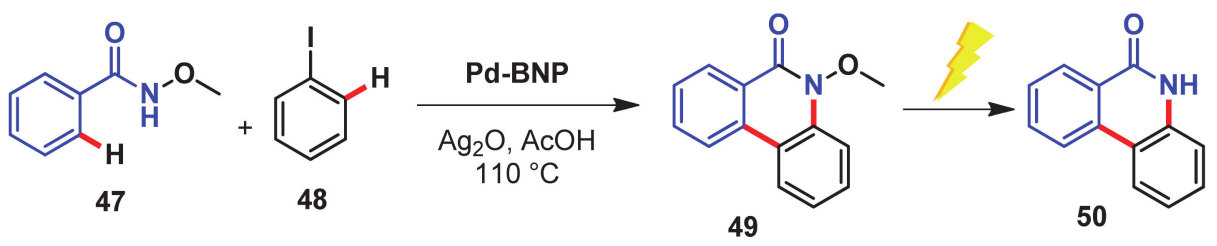

Scheme 18. Synthesis of phenanthridinones catalyzed by Pd-BNP.

A Pd NP catalyst was also developed by Maji, Maiti and coworkers and employed in the synthesis of 2-substituted $N$-aryl indoles 53 (Scheme 19) [84]. The catalyst consists of Pd NPs stabilized on $\alpha$-Synuclein ( $\alpha$-Syn) fibrils showing good performance in the synthesis of 53 via triple $C-H$ activation between the $N$-phenyl anilines 51 and the terminal alkenes 52. The synergy between thes amyloid fibrils and Pd NPs was crucial, as proven by control experiments conducted in the absence of, or varying the support or the structure of, the fibril. Under the optimized conditions, the catalyst could be recovered and reused for three consecutive runs with no change in the morphology of the Pd NPs, while at the same time a slight modification in the amyloid fibril structure was observed. 


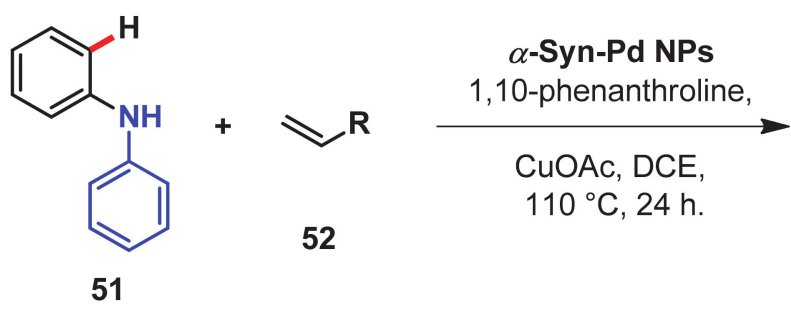

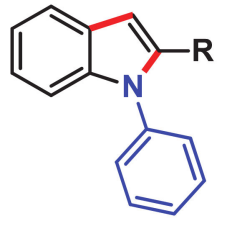

53

Scheme 19. Synthesis of 53 catalyzed by $\alpha$-Syn-Pd NPs.

\section{Conclusions and Future Outlooks}

The direct construction of novel $\mathrm{C}-\mathrm{N}$ bond is of great interest in different areas leading to an atom-economical strategy to access high-value products. The precious metals, generally used as homogenous catalytic systems, could possibly be replaced with more convenient heterogeneous systems that allow for an easy separation of the catalyst from the reaction mixture, the reuse of the catalytic system and a minimization of product metal contamination.

In this contribution, we focused on the employment of metal nanoparticles as heterogeneous catalytic systems. Metal choice and the selection of the most appropriate support are generally the pivotal parameters to define efficient nanocatalytic systems, and this is also true in the formation of $\mathrm{C}-\mathrm{N}$ bonds via $\mathrm{C}-\mathrm{H}$ activation. Indeed, catalyst design at nanometric size enhances the catalytic performance of otherwise less-reactive non-noble hearth-abundant metals. The preparation and use of MNPs can be also seen as a sustainable approach for the use of low-abundant noble metals in direct $\mathrm{C}-\mathrm{N}$ bond formation and for eventual catalyst recovery.

The literature concerning $\mathrm{C}-\mathrm{H}$ amidation reactions is dominated by protocols employing 3d-metal NP ( $\mathrm{Co}$ and $\mathrm{Cu}$ ) or their oxides $(\mathrm{CuO})$, and the same goes for $\mathrm{C}-\mathrm{H}$ amination $(\mathrm{Fe}, \mathrm{Cu}$ and $\mathrm{CuO})$. Rare are the examples of $\mathrm{Pd}$ - or $\mathrm{Ru}$-based catalysts. In the exploitation of $\mathrm{C}-\mathrm{N}$ bond formation for the synthesis of heterocycles (last section), the majority of the contributions report the use of Pd NP catalysts.

When using a solid catalyst, the definition of the actual active mechanism may be non-trivial. When possible in the discussed examples, the experiments performed to determinate the rate-determining step and the role of MNPs in the catalytic cycle were discussed.

In the realm of $\mathrm{C}-\mathrm{N}$ bond formation via $\mathrm{C}-\mathrm{H}$ functionalization catalyzed by MNPs, there are few examples reporting the use of photocatalysis to improve catalyst performance. To the best of our knowledge, the combination of nanocatalysis with other enabling technologies has not been reported. While MNP-catalyzed direct $\mathrm{C}-\mathrm{N}$ bond formation can benefit from the use of flow chemistry, microwave or ultrasound activations can also help to scale-up the procedure. The engineering of nanocatalysts and their synergy with novel methodologies are expected to improve this process from a sustainability point of view.

Author Contributions: Writing—review and editing, F.V., O.P. and L.V. All authors have read and agreed to the published version of the manuscript.

Funding: MIUR: AMIS—“Dipartimenti di Eccellenza-2018-2022”.

Acknowledgments: The Università degli Studi di Perugia and MIUR are acknowledged for financial support to the project AMIS, through the program "Dipartimenti di Eccellenza-2018-2022".

Conflicts of Interest: The authors declare no conflict of interest.

\section{References}

1. Ballini, R. (Ed.) Green Synthetic Processes and Procedures; Royal Society of Chemistry: Croydon, UK, 2019 ; Volume 61.

2. Sheldon, R.A.; Arends, I.; Hanefeld, U. Green Chemistry and Catalysis; John Wiley \& Sons: Weinheim, Germany, 2007.

3. Dalton, T.; Faber, T.; Glorius, F. C-H activation: Toward sustainability and applications. ACS Cent. Sci. 2021, 7, 245-261. [CrossRef] [PubMed] 
4. Santoro, S.; Ferlin, F.; Vaccaro, L. Sustainable Approaches to C-H Functionalizations Through Flow Techniques-Flow Chemistry; RSC Green Chemistry: Cambridge, UK, 2020; pp. 199-216.

5. Santoro, S.; Ferlin, F.; Ackermann, L.; Vaccaro, L. C-H functionalization reactions under flow conditions. Chem. Soc. Rev. 2019, 48, 2767-2782. [CrossRef]

6. Santoro, S.; Marrocchi, A.; Lanari, D.; Ackermann, L.; Vaccaro, L. Towards sustainable C-H functionalization reactions: The emerging role of bio-based reaction media. Chem. Eur. J. 2018, 24, 13383-13390. [CrossRef] [PubMed]

7. Goldberg, K.I.; Goldman, A.S. Large-scale selective functionalization of alkanes. Acc. Chem. Res. 2017, 50, 620-626. [CrossRef] [PubMed]

8. Crabtree, R.H.; Lei, A. Introduction: CH activation. Chem. Rev. 2017, 117, 8481-8482. [CrossRef]

9. Davies, H.M.L.; Morton, D. Recent advances in C-H functionalization. J. Org. Chem. 2016, 81, 343-350. [CrossRef]

10. Girard, S.A.; Knauber, T.; Li, C.-J. The cross-dehydrogenative coupling of $\mathrm{Csp}_{3}-\mathrm{H}$ bonds: A versatile strategy for C-C bond formations. Angew. Chem. Int. Ed. 2014, 53, 74-100. [CrossRef]

11. Rouquet, G.; Chatani, N. Catalytic functionalization of $\mathrm{C}\left(\mathrm{sp}_{2}\right)-\mathrm{H}$ and $\mathrm{C}\left(\mathrm{sp}_{3}\right)-\mathrm{H}$ bonds by using bidentate directing groups. Angew. Chem. Int. Ed. 2013, 52, 11726-11743. [CrossRef]

12. Wencel-Delord, J.; Glorius, F. C-H bond activation enables the rapid construction and latestage diversification of functional molecules. Nat. Chem. 2013, 5, 369-375. [CrossRef]

13. Yeung, C.S.; Dong, V.M. Catalytic dehydrogenative cross-coupling: Forming carbon-carbon bonds by oxidizing two carbonhydrogen bonds. Chem. Rev. 2011, 111, 1215-1292. [CrossRef]

14. Dyker, G. (Ed.) Handbook of C-H Transformations: Applications in Organic Synthesis; Wiley-VCH Verlag GmbH \& Co. KGaA: Weinheim, Germany, 2005; Volume 2.

15. Crabtree, R.H.A.E. Shilov's influence on early work in organometallic $\mathrm{CH}$ activation and functionalization. J. Organomet. Chem. 2015, 793, 41-46. [CrossRef]

16. Li, J.J. C-H Bond Activation in Organic Synthesis; CRC Press: Boca Raton, FL, USA, 2015.

17. Shilov, A.E.; Shul'pin, G.B. Activation of C-H bonds by metal complexes. Chem. Rev. 1997, 97, 2879-2932. [CrossRef]

18. Guo, X.-X. Copper-Catalyzed C-H Activation. In Copper Catalysis in Organic Synthesis; Anilkumar, G., Saranya, S., Eds.; Wiley-VCH Verlag GmbH \& Co. KGaA: Weinheim, Germany, 2020; pp. 329-348.

19. Zhang, M.; Wang, Q.; Peng, Y.; Chen, Z.; Wan, C.; Chen, J.; Zhao, Y.; Zhang, R.; Zhang, A.Q. Transition metal-catalyzed sp 3 C-H activation and intramolecular $\mathrm{C}-\mathrm{N}$ coupling to construct nitrogen heterocyclic scaffolds. Chem. Commun. 2019, 55, 13048-13065. [CrossRef]

20. Borpatra, P.J.; Deka, B.; Deb, M.L.; Baruah, P.K. Recent advances in intramolecular C-O/C-N/C-S bond formation via C-H functionalization. Org. Chem. Front. 2019, 6, 3445-3489. [CrossRef]

21. Gandeepan, P.; Kaplaneris, N.; Santoro, S.; Vaccaro, L.; Ackermann, L. Biomass-Derived Solvents for Sustainable Transition Metal-Catalyzed C-H Activation. ACS Sustain. Chem. Eng. 2019, 7, 8023-8040. [CrossRef]

22. Gandeepan, P.; Muller, T.; Zell, D.; Cera, G.; Warratz, S.; Ackermann, L. 3d Transition metals for C-H activation. Chem. Rev. 2019, 119, 2192-2452. [CrossRef]

23. Chu, J.C.K.; Rovis, T. Complementary strategies for directed C(sp3)-H functionalization: A comparison of transition-metalcatalyzed activation, hydrogen atom transfer, and carbene/nitrene transfer. Angew. Chem. Int. Ed. 2018, 57, 62-101. [CrossRef]

24. Gandeepan, P.; Ackermann, L. Transient directing groups for transformative C-H activation by synergistic metal catalysis. Chem 2018, 4, 199-222. [CrossRef]

25. Arockiam, P.B.; Bruneau, C.; Dixneuf, P.H. Ruthenium(II)-catalyzed C-H bond activation and functionalization. Chem. Rev. 2012, 112, 5879-5918. [CrossRef]

26. Hashiguchi, B.G.; Bischof, S.M.; Konnick, M.M.; Periana, R.A. Designing catalysts for functionalization of unactivated C-H bonds based on the $\mathrm{CH}$ activation reaction. Acc. Chem. Res. 2012, 45, 885-898. [CrossRef]

27. Kim, K.; Jung, Y.; Lee, S.; Kim, M.; Shin, D.; Byun, H.; Cho, S.J.; Song, H.; Kim, H. Directed C- H activation and tandem cross-coupling reactions using palladium nanocatalysts with controlled oxidation. Angew. Chem. Int. Ed. 2017, 56, 6952-6956. [CrossRef]

28. Ferlin, F.; Luque Navarro, P.M.; Gu, Y.; Lanari, D.; Vaccaro, L. Waste minimized synthesis of pharmaceutically active compounds via heterogeneous manganese catalysed C-H oxidation in flow. Green Chem. 2020, 22, 397-403. [CrossRef]

29. Ferlin, F.; van der Hulst, M.K.; Santoro, S.; Lanari, D.; Vaccaro, L. Continuous flow/waste minimized synthesis of benzoxazoles catalysed by heterogeneous manganese systems. Green Chem. 2019, 21, 5298-5305. [CrossRef]

30. Ferlin, F.; Yetra, S.R.; Warratz, S.; Vaccaro, L.; Ackermann, L. Reusable Pd@PEG catalyst for aerobic dehydrogenative C-H/C-H arylations of 1,2,3-triazoles. Chem. Eur. J. 2019, 25, 11427-11431. [CrossRef]

31. Sciosci, D.; Valentini, F.; Ferlin, F.; Chen, S.; Gu, Y.; Piermatti, O.; Vaccaro, L. A heterogeneous and recoverable palladium catalyst to access the regioselective C-H alkenylation of quinoline N-oxides. Green Chem. 2020, 22, 6560-6566. [CrossRef]

32. Asensio, J.M.; Bouzouita, D.; van Leeuwen, P.W.N.M.; Chaudret, B. $\sigma-\mathrm{H}-\mathrm{H}, \sigma-\mathrm{C}-\mathrm{H}$, and $\sigma-\mathrm{Si}-\mathrm{H}$ bond activation catalyzed by metal nanoparticles. Chem. Rev. 2020, 120, 1042-1084. [CrossRef]

33. Dhakshinamoorthy, A.; Asiri, A.M.; Garcia, H. Formation of C-C and C-heteroatom bonds by $\mathrm{C}-\mathrm{H}$ activation by metal organic frameworks as catalysts or supports. ACS Catal. 2019, 9, 1081-1102. [CrossRef] 
34. Liu, M.; Wu, J.; Hou, H. Metal-organic framework (MOF)-based materials as heterogeneous catalysts for C-H bond activation. Chem. Eur. J. 2019, 25, 2935-2948. [CrossRef]

35. Pla, D.; Gómez, M. Metal and metal oxide nanoparticles: A lever for C-H functionalization. ACS Catal. 2016, 6, 3537-3552. [CrossRef]

36. Reay, A.J.; Fairlamb, I.J.S. Catalytic C-H bond functionalisation chemistry: The case for quasi-heterogeneous catalysis. Chem. Commun. 2015, 51, 16289-16307. [CrossRef] [PubMed]

37. Valentini, F.; Brufani, G.; Latterini, L.; Vaccaro, L. Metal nanoparticles catalyzed C-C bond formation via C-H activation. In Advanced Heterogeneous Catalysts Volume 1: Applications at the Nano-Scale; American Chemical Society: Washington, DC, USA, 2020; pp. 513-543. [CrossRef]

38. Fairlamb, I.J.S.; Scott, N.W.J. Pd Nanoparticles in C-H Activation and Cross-coupling Catalysis. In Nanoparticles in Catalysis; Springer: Cham, Switzerland, 2020; pp. 171-205. [CrossRef]

39. Serp, P.; Philippot, K. (Eds.) Nanomaterials in Catalysis; Wiley-VCH Verlag GmbH \& Co. KGaA: Weinheim, Germany, 2013.

40. Astruc, D. Nanoparticles and Catalysis; Wiley-VCH Verlag GmbH \& Co. KGaA: Weinheim, Germany, 2008.

41. Heiz, U.; Landman, U. (Eds.) Nanocatalysis; Springer: Berlin/Heidelberg, Germany, 2007.

42. Cao, G.; Wang, Y. Nanostructures and Nanomaterials: Synthesis, Properties and Applications, 2nd ed.; World Scientific Series in Nanoscience and Nanotechnology; World Scientific Pub Co Inc. Imperial College Press: London, UK, 2011 ; Volume 2.

43. Calvino-Casilda, V.; Lopez-Peinado, A.J.; Martin-Aranda, R.M.; Mayoral, E.P. (Eds.) Nanocatalysis: Applications and Technologies; CRC Press: Boca Raton, FL, USA, 2019.

44. Chopra, R.; Kumar, M.; Bhalla, V. Development of a supramolecular ensemble of an AIEE active hexaphenylbenzene derivative and $\mathrm{Ag} @ \mathrm{Cu}_{2} \mathrm{O}$ core-shell NPs: An efficient photocatalytic system for $\mathrm{C}-\mathrm{H}$ activation. Chem. Commun. 2016, 52, 10179-10182. [CrossRef] [PubMed]

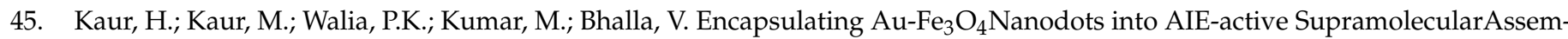
blies:Ambient Visible-light Harvesting “Dip-Strip" Photocatalyst for C-C/C-N Bond Formation Reactions. Chem. Asian J. 2019, 14, 809-813. [CrossRef] [PubMed]

46. Lee, J.; Chung, J.; Byun, S.M.; Kim, B.M.; Lee, C. Direct catalytic C-H arylation of imidazo[1,2- $\alpha$ ]pyridine with aryl bromides using magnetically recyclable $\mathrm{Pd}-\mathrm{Fe}_{3} \mathrm{O}_{4}$ nanoparticles. Tetrahedron 2013, 69, 5660-5664. [CrossRef]

47. Kaur, S.; Kumar, M.; Bhalla, V. Aggregates of perylene bisimide stabilized superparamagnetic $\mathrm{Fe}_{3} \mathrm{O}_{4}$ nanoparticles: An efficient catalyst for the preparation of propargylamines and quinolines via $\mathrm{C}-\mathrm{H}$ activation. Chem. Commun. 2015, 51, 16327-16330. [CrossRef] [PubMed]

48. Nguyen, A.T.; Pham, L.T.; Phan, N.T.S.; Truong, T. Efficient and robust superparamagnetic copper ferrite nanoparticle-catalyzed sequential methylation and $\mathrm{C}-\mathrm{H}$ activation: Aldehyde free propargylamine synthesis. Catal. Sci. Technol. 2014, 4, 4281-4288. [CrossRef]

49. Rafiee, F.; Rezaie, F. Karder, Bio-crosslinking of chitosan with oxidized starch, its functionalization with amino acid and magnetization: As a green magnetic support for silver immobilization and its catalytic activity investigation. Int. J. Biol. Macromol. 2020, 146, 1124-1132. [CrossRef]

50. Veisi, H.; Mohammadi, L.; Hemmati, S.; Tamoradi, T.; Mohammadi, P. In situ immobilized silver nanoparticles on rubia tinctorum extract-coated ultrasmall iron oxide nanoparticles: An efficient nanocatalyst with magnetic recyclability for synthesis of propargylamines by A3 coupling reaction. ACS Omega 2019, 4, 13991-14003. [CrossRef]

51. Aghahosseini, H.; Rezaei, S.J.T.; Tadayyon, M.; Ramazani, A.; Amani, V.; Ahmadi, R.; Abdolahnjadian, D. Highly efficient aqueous synthesis of propargylamines through $\mathrm{C}-\mathrm{H}$ activation catalyzed by magnetic organosilica-supported gold nanoparticles as an artificial metalloenzyme. Eur. J. Inorg. Chem. 2018, 2589-2598. [CrossRef]

52. Gulati, U.; Rajesh, U.C.; Rawat, D.S. CuO/ $\mathrm{Fe}_{2} \mathrm{O}_{3}$ NPs: Robust and magnetically recoverable nanocatalyst for decarboxylative A3 and KA2 coupling reactions under neat conditions. Tetrahedron Lett. 2016, 57, 4468-4472. [CrossRef]

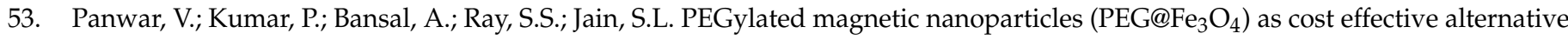
for oxidative cyanation of tertiary amines via C-H activation. Appl. Catal. A: Gen. 2015, 498, 25-31. [CrossRef]

54. Gruttadauria, M.; Giacalone, F.; Noto, R. "Release and catch" catalytic systems. Green Chem. 2013, 15, 2608-2618. [CrossRef]

55. Fairlamb, I.J.S.; Lee, A.F. Fundamental Pd(0)/Pd(II) redox steps in cross-coupling reactions: Homogeneous, hybrid homogeneousheterogeneous to heterogeneous mechanistic pathways for $\mathrm{C}-\mathrm{C}$ couplings. In Catalytic $\mathrm{C}-\mathrm{H} / \mathrm{C}-\mathrm{X}$ Bond. Functionalization: Transition Metal. Mediation; Ribas, X., Ed.; RSC Catalysis Series; RSC Publishing: Cambridge, UK, 2013; pp. $72-107$.

56. Song, S.-Z.; Meng, Y.-N.; Li, Q.; Wei, W.-T. Recent progress in the construction of C-N bonds via metal-free radical C(sp $\left.{ }^{3}\right)-H$ functionalization. Adv. Synth. Catal. 2020, 362, 2120-2134. [CrossRef]

57. Timsina, Y.N.; Gupton, B.F.; Ellis, K.C. Palladium-catalyzed C-H amination of C( $\left.\mathrm{sp}^{2}\right)$ and $\mathrm{C}\left(\mathrm{sp}^{3}\right)-\mathrm{H}$ bonds: Mechanism and scope for N-based molecule synthesis. ACS Catal. 2018, 8, 5732-5776. [CrossRef]

58. Henry, M.C.; Mostafa, M.A.; Sutherland, A. Recent advances in transition-metal-catalyzed, directed aryl C-H/N-H cross-coupling reactions. Synthesis 2017, 49, 4586-4598. [CrossRef]

59. Dauban, P.; Darses, B. C-N Bond Formation by Arene C-H Activation Using a Palladium Catalyst. In Catalytic Transformations via C-H Activation; Yu, J.-Q., Ed.; Georg Thieme Verlag KG: New York, NY, USA, 2015; Volume 2, pp. 221-248.

60. Harry, N.A.; Jagadeesh, R.V. Copper-Catalyzed Aminations. In Copper Catalysis in Organic Synthesis; Anilkumar, G., Saranya, S., Eds.; Wiley-VCH Verlag GmbH \& Co. KGaA: Weinheim, Germany, 2020; pp. 239-259. 
61. Bai, C.; Yao, X.; Li, Y. Easy access to amides through aldehydic C-H bond functionalization catalyzed by heterogeneous Co-based catalysts. ACS Catal. 2015, 5, 884-891. [CrossRef]

62. Gava, R.; Biffis, A.; Tubaro, C.; Zaccheria, F.; Ravasio, N. Heterogeneous copper-based catalysts for the amidation of activated C-H bonds. Catal. Commun. 2013, 40, 63-65. [CrossRef]

63. Singh, H.; Sahoo, T.; Sen, C.; Galani, S.M.; Ghosh, S.C. Aerobic oxidative alkynylation of H-phosphonates and amides: An efficient route for the synthesis of alkynylphosphonates and ynamides using a recyclable $\mathrm{Cu}-\mathrm{MnO}$ catalyst. Catal. Sci. Technol. 2019, 9, 1691-1698. [CrossRef]

64. Singh, H.; Sen, C.; Suresh, E.; Panda, A.B.; Ghosh, S.C. C-H amidation and amination of arenes and heteroarenes with amide and amine using $\mathrm{Cu}-\mathrm{MnO}$ as a reusable catalyst under mild conditions. J. Org. Chem. 2021, 86, 3261-3275. [CrossRef]

65. Meng, X.; Wang, Y.; Wang, Y.; Chen, B.; Jing, Z.; Chen, G.; Zhao, P. OMS-2-supported Cu hydroxide-catalyzed benzoxazoles synthesis from catechols and amines via domino oxidation process at room temperature. J. Org. Chem. 2017, 82, 6922-6931. [CrossRef] [PubMed]

66. Meng, X.; Yu, C.; Chen, G.; Zhao, P. Heterogeneous biomimetic aerobic synthesis of 3-iodoimidazo[1,2-a]pyridines via CuO $x /$ OMS2-catalyzed tandem cyclization/iodination and their late-stage functionalization. Catal. Sci. Technol. 2015, 5, 372-379. [CrossRef]

67. Biswas, S.; Mullick, K.; Chen, S.-Y.; Kriz, D.A.; Shakil, M.D.; Kuo, C.-H.; Angeles-Boza, A.M.; Rossi, A.R.; Suib, S.L. Mesoporous copper/manganese oxide catalyzed coupling of alkynes: Evidence for synergistic cooperative catalysis. ACS Catal. 2016, 6, 5069-5080. [CrossRef]

68. Oishi, T.; Yamaguchi, K.; Mizuno, N. Conceptual design of heterogeneous oxidation catalyst: Copper hydroxide on manganese oxide-based octahedral molecular sieve for aerobic oxidative alkyne homocoupling. ACS Catal. 2011, 1, 1351-1354. [CrossRef]

69. Chng, L.L.; Zhang, J.; Yang, J.; Amoura, M.; Ying, J.Y. C-C bond formation via C-H activation and C-N bond formation via oxidative amination catalyzed by palladium- polyoxometalate nanomaterials using dioxygen as the terminal oxidant. Adv. Synth. Catal. 2011, 353, 2988-2998. [CrossRef]

70. He, J.; Dhakshinamoorthy, A.; Primo Arnau, A.M.; García Gómez, H. Iron nanoparticles embedded in graphitic carbon matrix as heterogeneous catalysts for the oxidative CN coupling of aromatic NH compounds and amides. Chem. Cat. Chem. 2017, 9, 3003-3012. [CrossRef]

71. Priyadarshini, S.; Joseph, P.A.; Kantam, M.L. Copper catalyzed oxidative cross-coupling of aromatic amines with 2-pyrrolidinone: A facile synthesis of N-aryl- $\gamma$-amino- $\gamma$-lactams. Tetrahedron 2014, 70, 6068-6074. [CrossRef]

72. Kaur, S.; Kumar, M.; Bhalla, V. Supramolecular ensemble of PBI derivative and copper nanoparticles: A light harvesting antenna for photocatalytic C (sp2)-H functionalization. Green Chem. 2016, 18, 5870-5883. [CrossRef]

73. Satish, G.; Reddy, K.H.V.; Anil, B.S.P.; Shankar, J.; Kumar, R.U.; Nageswar, Y.V.D. Direct C-H amination of benzothiazoles by magnetically recyclable $\mathrm{CuFe}_{2} \mathrm{O}_{4}$ nanoparticles under ligand-free conditions. Tetrahedron Lett. 2014, 55, 5533-5538. [CrossRef]

74. Singh, H.; Pal, P.; Sen, C.; Panda, A.B.; Ghosh, S.C. Heterogeneous Cu-MnO-Catalyzed Direct C-H Amination of Azoles Using O 2 as the Sole Oxidant. Asian J. Org. Chem. 2017, 6, 702-706. [CrossRef]

75. Acharyya, S.S.; Ghosh, S.; Bal, R. Direct catalytic oxyamination of benzene to aniline over Cu(II) nanoclusters supported on $\mathrm{CuCr}_{2} \mathrm{O}_{4}$ spinel nanoparticles via simultaneous activation of $\mathrm{C}-\mathrm{H}$ and $\mathrm{N}-\mathrm{H}$ bonds. Chem. Commun. 2014, 50, 13311-13314. [CrossRef]

76. Pal, P.; Giri, A.K.; Singh, H.; Ghosh, S.C.; Panda, A.B. Heterogeneously porous $\gamma-\mathrm{MnO}_{2}$-catalyzed direct oxidative amination of benzoxazole through $\mathrm{C}-\mathrm{H}$ activation in the presence of $\mathrm{O}_{2}$. Chem. Asian J. 2014, 9, 2392-2396. [CrossRef]

77. Wang, Y.; Furukawa, S.; Song, S.; He, Q.; Asakura, H.; Yan, N. Catalytic production of alanine from waste glycerol. Angew. Chem. Int. Ed. 2020, 59, 2289-2293. [CrossRef] [PubMed]

78. Modi, A.; Ali, W.; Mohanta, P.R.; Khatun, N.; Patel, B.K. CuO nanoparticle catalyzed synthesis of 2,3-disubstituted quinazolinones via sequential N-Arylation and oxidative C-H amidation. ACS Sustain. Chem. Eng. 2015, 3, 2582-2590. [CrossRef]

79. Chng, L.L.; Yang, J.; Wei, Y.; Ying, J.Y. Palladium nanomaterials in catalytic intramolecular C-H amination reactions. Chem. Commun. 2014, 50, 9049-9052. [CrossRef] [PubMed]

80. Takagi, K.; Al-Amin, M.; Hoshiya, N.; Wouters, J.; Sugimoto, H.; Shiro, Y.; Fukuda, H.; Shuto, S.; Arisawa, M. Palladiumnanoparticle-catalyzed 1, 7-palladium migration involving C-H activation, followed by intramolecular amination: Regioselective synthesis of N 1-arylbenzotriazoles and an evaluation of their inhibitory activity toward indoleamine 2, 3-dioxygenase. J. Org. Chem. 2014, 79, 6366-6371. [CrossRef]

81. Chen, J.; He, L.; Natte, K.; Neumann, H.; Beller, M.; Wu, X.-F. Palladium@Cerium(IV) oxide-catalyzed oxidative synthesis of n-(2-pyridyl)indoles via C-H activation reaction. Adv. Synth. Catal. 2014, 356, 2955-2959. [CrossRef]

82. Reddy, P.V.; Annapurna, M.; Srinivas, P.; Likhar, P.R.; Kantam, M.L. Nanocrystalline magnesium oxide-stabilized palladium (0): An efficient and reusable catalyst for synthesis of N-(2-pyridyl) indoles. New J. Chem. 2015, 39, 3399-3404. [CrossRef]

83. Saha, R.; Sekar, G. Stable Pd-nanoparticles catalyzed domino CH activation/CN bond formation strategy: An access to phenanthridinones. J. Catal. 2018, 366, 176-188. [CrossRef]

84. Jayarajan, R.; Kumar, R.; Gupta, J.; Dev, G.; Kadu, P.; Chatterjee, D.; Bahadur, D.; Maiti, D.; Maji, S.K. Fabrication of an amyloid fibril-palladium nanocomposite: A sustainable catalyst for $\mathrm{C}-\mathrm{H}$ activation and the electrooxidation of ethanol. J. Mater. Chem. A 2019, 7, 4486-4493. [CrossRef] 